\title{
Momentum and Its Implications in Corporate Management
}

\author{
Tsutomu Ito", Katsuhiko Takahashi, Katsumi Morikawa, Takao Ito \\ Graduate School of Engineering, Hiroshima University, 1-4-1 Kagamiyama \\ Higashi-Hiroshima, Hiroshima 739-8527, Japan \\ Rajiv Mehta \\ School of Management, New Jersey Institute of Technology University Height \\ Newark, NJ 07102-1982 USA \\ Sakamoto Makoto, Satoshi Ikeda \\ Faculty of Engineering University of Miyazaki 1-1, Gakuenkibanadai-nishi \\ Miyazaki, 889-2192 JAPAN \\ *Corresponding author, E-mail: fw.eldorado.500cuin@gmail.com \\ Tel: +81-82-424-5594, Fax: +81-82-424-5594
}

\begin{abstract}
The current manuscript reviews the literature associated with corporate strategy, and proposes a new approach of acceleration to measure momentum based on limited cycle theory. Thus, this research manuscript makes a contribution to extant thought by: 1) Defining momentum, 2) Discussing the nature of the relationship between momentum to its external environment, and company scale, 3) Ascertaining the momentum period, and 4) Proposing a four-cell model composed of momentum and company scale for judging a firm's position. Additionally, the relationship between momentum and the impact of 2007-2008 financial crises is addressed. Based on the findings, the study limitations are identified and directions for further research are suggested.
\end{abstract}

Keywords: Momentum, velocity, limit cycle theory, four cell model, strategy

\section{Introduction}

The basis of corporate strategy stems from two seminal books: The Art of War, and On War written by Sun Tzu in the late sixth century BC and Carl von Clausewitz in 1827, respectively. In comparing these two books, especially the Art of War, with extant strategic theories, discussions on momentum, an important concept, have been sparse, although in the context of current management strategies, the pivotal nature of momentum recently has been operationalized and discussed in research on marketing, and finance. This paper reviews the literature associated with corporate strategy to propose a new approach of acceleration for measuring momentum based on limited cycle theory. This research also attempts to shed light on the relationship between sales revenue and momentum, and offers an explanation why the business cycle in Japan's automobile industry changed to a four-year period. Furthermore, the paper also develops a four cell model comprising momentum and firm scale as an effective approach for improving corporate performance.

This paper is structured as follows. Section 2 reviews the literature focusing on the momentum and corporate management. In section 3, the paper explicates the calculation process of momentum and data collection. Section 4 discusses our findings and managerial implications based upon our calculation. The study limitations are identified and directions for further research are proffered in Section 5. 


\section{Background}

Momentum is a term to express power, force and speed of organizational movement. The original description of momentum appears in Art of War written by famous strategist Sun Tzu. Indicating the importance of momentum at the beginning of his book, Sun Tzu famously asserts: It is important to "look for advantages when applying my principles and you will gather sufficient force to take on unforeseen situations. Force is tilting the balance of power to your side by gathering advantages" to win any battle [1, 01.11-01.12]. He continued to explain the meaning of momentum in chapter five as force. In this context, he asserts "the rush of torrential waters tossing boulders illustrates force. The strike of a bird of prey breaking the body of its target illustrates timing. Therefore, the force of those skilled in warfare is overwhelming and their timing precise. Their force is like a drawn crossbow and their timing is like the release of the trigger" [1, 05.08-05.10]. Furthermore, in analyzing the relationship between the momentum and war, Sun Tzu, posits "Those skilled in warfare seek victory through force and do not require too much from individuals. Therefore, they are able to select the right men and exploit force. One who exploits force commands men into battle like rolling logs and boulders. Logs and boulders are still when on flat ground, but roll when on steep ground. Square shapes are still, but round shapes roll. Therefore, those skilled in warfare use force by making the troops in battle like boulders rolling down a steep mountain. This is force" [1, 05.16-05.18].

It is widely acknowledged that military strategy forms the basis of corporate strategy. But in the strategic management literature, surprisingly there is no theoretical description nor application of momentum, which plays an important role in the performance of business activities. An on-line browse of the term "strategy momentum" (in Japanese) yielded approximately 932,000 hits which suggest that it obviously is an important concept in corporate strategy.

Momentum expresses a force or speed of movement. In this paper, momentum is defined as a force or impetus of firms to maintain firm's development durability in certain period. Why is momentum becoming more and more important? A possible explanation is that inherent uncertainty is in-built within the dynamic, high-speed global economy. With the high rate of innovation, the speed of decision-making has become a condition for successful performance.

In 1995, as a new method applying business to U.S. army logistics, velocity management focused on improving the speed and accuracy with which materials and information flow from providers to users. Meanwhile, velocity management is an emergent scientific field that conflates army' operations and business together to reflect the new realities of the global environment. Mourier observed that velocity management is decision making at speeds consistent with today's competitive environment and technology [2].

It is noteworthy that momentum has been the subject of study in finance and marketing. Momentum in stock and securities is used to illustrate that their price is more likely to keep moving in the same direction than to change directions. In technical analysis, momentum is considered as an oscillator and is used to help identify trend lines. It is the empirically observed tendency for rising asset prices to rise further, and falling prices to keep falling. One of the important achievements in finance is that stocks with strong past performance continue to outperform stocks with poor past performance in the next period with an average excess return of about $1 \%$ per month [3].

However, to our best knowledge, this is the first work that shows how to calculate momentum using velocity for corporate strategy. The basic reasons why we have to calculate momentum using limit cycle theory because the global economy is becoming increasingly uncertain and most of the corporate behaviors are non-linear. This body of thought is important as it will help increase our understanding and provide guidance that strategic management practitioners can use to increase organizational performance. Thus, this study addresses the paucity in the strategic management literature and makes a contribution to the filed by being the first, initial, investigation that illustrates how to measure momentum using velocity, and its observed importance for corporate strategy.

\section{Measurement and Data Collection}

In this section, previous studies have showed that chaos, which is generally described as a disorder state, is driven by deterministic nonlinear processes, such as hydraulic flow and astronomical phenomena. Findings in physics and biology have discovered some examples of chaos. For example, Tsuda et al, found a chaotic 
pulsation in a finger's capillary vessels in normal subjects and psychiatric patients, as well as cardiac chaos [4].

Additional research illustrated that chaotic movement is not only applicable in physics and biology, but also in sociology and management science. For instance, Priesmeyer and Baik proposed a new method to discover the pattern of chaos in 1989. They noticed that organization have characteristics limit cycle like the human heart. They indicated "Company data tend to adhere to an attractor as they collect their quarterly sales and drive their quarterly profits. One can almost hear the organizational heartbeat pounding out 'Quarter 1, Quarter 2, Quarter 3, Quarter 4"' [5]. Furthermore, Ito and Sakamoto shed light on the nature of the relationship between economic development and the velocity history of the typical companies in Japan [6].

Because most of the behaviors of the firms are nonlinear, momentum should be calculated based on complex systems theory. In this paper, momentum is conceptualized as a force that composed of sales and profit movement, and is calculated based upon limit cycle theory because of its non-linear movement.

In order to calculate and assess the impact of momentum on corporate performance, data were collected from 35 selected companies, including 10 car makers and 25 parts suppliers. In order to understand the impacts of the Lehman shock on momentum, the data includes sales and profit from 2003 to 2013.

\section{Discussions and Analysis}

The $t$ in Momentum equation may vary depending on different analysis proposed. For instance, one-year momentum is calculated when $\mathrm{t}$ is equal to 1 , and two-year momentum is calculated when $t$ is equal to 2 . To understand the movement of the momentum within a short period, one-year momentum is calculated as below.

All momentum looks very stable except the period from 2007 to 2010. As a well-known fact, 2007-2008 financial crisis resulted from subprime lending practices. The prospects of Japan's economy are unpredictable and the sales of new decreased. The unstable momentum could be considered as a reaction of the financial crisis. Therefore, two conclusions are made based on observing Fig. 1. First, momentum is very sensitive to external changes. Another important fact is that momentum of Toyota increased in 2008, decreased in 2009, and recovered in 2010. Other car makers, such as Nissan and Mitsubishi, reacted similarly. Second, the financial crisis had an impact over three years on the Japanese car market. In other words, momentum could be considered as an effective index to calculate the environmental changes.

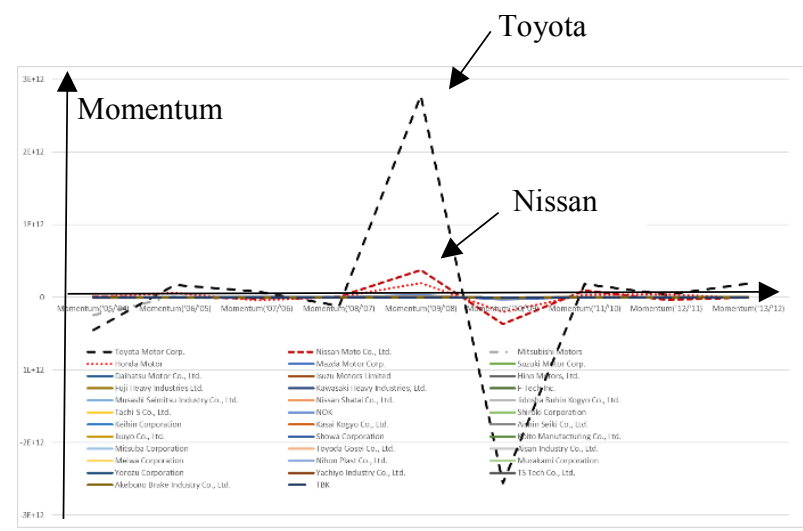

Fig. 1. One-year momentum of each firm (2005-2013).

Next, the multiple year momentum was calculated, which is illustrated in Fig. 2.

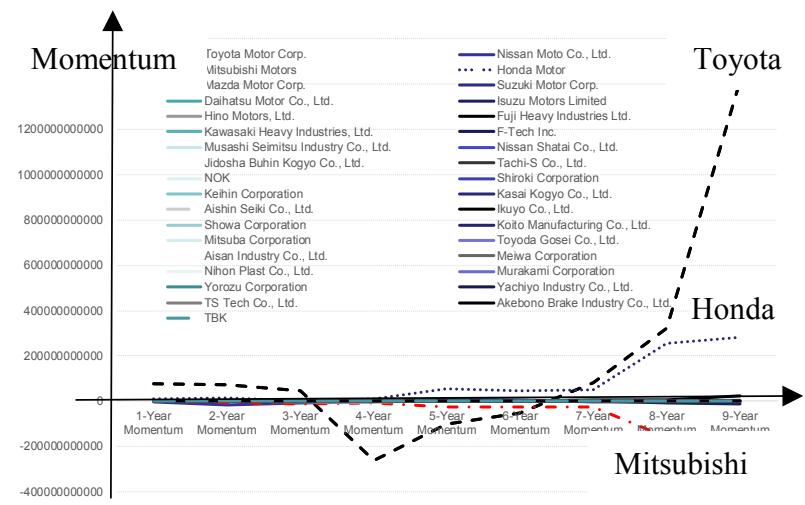

Fig. 2. 1-9 year Momentum of each firm (2005-2013).

In Fig. 2, Toyota is seen to have the biggest value for momentum over 9-years. The second is Honda, and the least is Mitsubishi. As time $t$ becomes longer, momentum of a big scale company grows larger. The third conclusion is that the reaction is apparently pronounced if the scale of the company is large.

The momentum of big scale companies shows large change, but all the others show stable change or marginal change. The four-year momentum has the highest effect on the sales in Fig. 3. Our conclusion is that this research offers an explanation why the model change cycle in Japan automobile industry changed to a four-year period. 


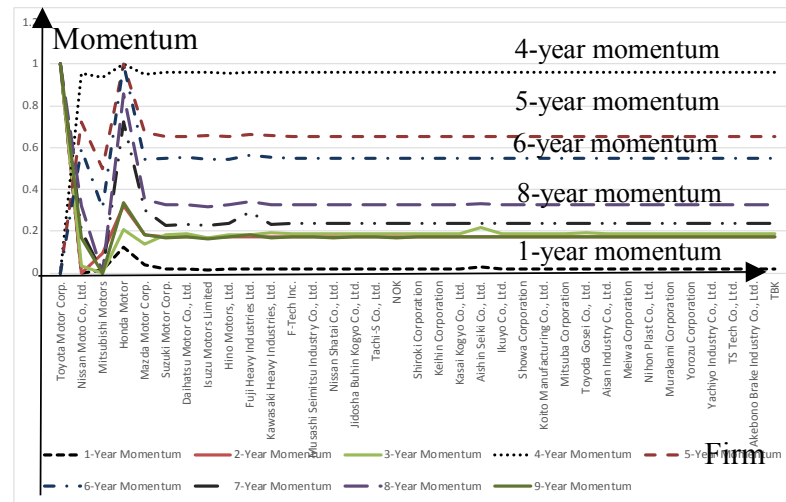

Fig. 3. Different Momentum of each firm (2005-2013).

Based on the results, it is also possible to identify successful companies as well as firms with impaired performance using momentum measurements. Based on the findings, momentum is influenced by the external environment, company scales, and corporate performance. Thus a four-cell model is proposed in this paper. Comprising of momentum and scale should be effective. The four-cell model of momentum ('13/'05) and sales 13 is illustrated in Fig. 4.

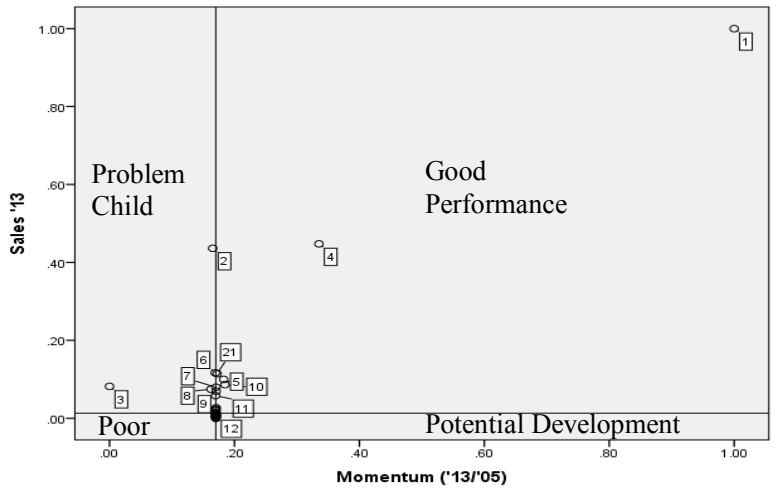

Fig. 4. A four-cell model of momentum ('13/'05) and Sales '13.

The reference line of $\mathrm{x}$ axis and $\mathrm{y}$ axis are the median of momentum and sales ' 13 respectively in Fig. 4 . The firms located in the 1st quadrant and the 3rd quadrant are good firms and poorly performing firms, respectively, because they have appropriate relationship between momentum and sales'13. The firm is called developing company with high development potential if it is located in 4th quadrant, while the firm is called problem child if it is located in 2nd quadrant. A firm moving from 3 rd quadrant to 2 nd or 4 th quadrant, or further from 2 nd and 4 th to 1 st quadrant would be considered positive signs. All the companies are divided into four different groups. Our next conclusion is that the four-cell model is appropriate to judge a firm's position.

\section{Conclusion}

This paper proposed a new approach for using momentum based on the limit cycle theory after reviewing the relevant literature. The relationship between momentum and its external changes, momentum and company scale were analyzed over various momentum periods. Furthermore, the four-cell model composed of momentum and company sales confirmed that it is effective for judging firm's position. Additionally, the impact of the financial crisis was also considered.

Sales and profit, as indices of corporate performance, is insufficient. Additional indices, such as aggregate market value and ROI (return on investment), should be investigated. What's more, in the future these models should be tested using data drawn from other settings, such as, information technology, the ship-building industry for comparative research as well as replicating the current findings.

\section{References}

1. Sun Tzu's The Art Of War, Translated by the Sonshi Group, https://www.sonshi.com/original-the-art-of-wartranslation-not-giles.html, Retrieved July 30, 2015.

2. Pierre Mourier, (2001), Velocity management: creating organizational instinct, Strategy \& Leadership, Vol. 29 Issue 2, pp. $24-28$.

3. Chakrabarti Gagari (2015) Time-series momentum trading strategies in the global stock market, Business, http://www.thefreelibrary.com/Time-series+momentum+ trading + strategies + in + the + global + stock + market-a042323 4977, Retrieved October 22, 2015.

4. Tsuda I., Tahara T., and Iwanaga H. (1992) Chaotic Pulsation in Human Capillary Vessels and its Dependence on Mental and Physical Conditions, International Journal of Bifurcation and Chaos, Vol.2, No.2, pp.313-324, World Scientific Publishing Company.

5. Priesmeyer H. R., Kibok Baik (1989) Discovering the Patterns of Chaos, Planning Review, pp.14-21 and pp.46-47, November/December 1989.

6. Ito T. and Sakamoto M. (2007) A Consideration on Limit Cycle Theory, The papers of Technical Meetings on Information Systems, IS-07-10, pp. 19-23, The Institute of Electrical Engineers of Japan (Japanese Edition). 